\title{
PENGARUH WORKPLACE FRIENDSHIP DAN PERSON-ORGANIZATION FIT (P-O FIT) TERHADAP ORGANIZATIONAL CITIZENSHIP BEHAVIOR (OCB) DENGAN KEPUASAN KERJA SEBAGAI VARIABEL INTERVENING
}

\author{
Rizki Barotuttakiah, Irfan Helmy \\ Sekolah Tinggi Ilmu Ekonomi Putra Bangsa
}

Email: rizkibarotuttakiah2@gmail.com

\begin{abstract}
Abstrak
Tujuan Penelitian ini untuk menganalisis pengaruh dari Workplace Friendship dan Person-Organization Fit Terhadap Organizational Citizenship Behavior melalui Kepuasan Kerja sebagai variabel intervening pada Dinas Perkim LH Kabupaten Kebumen. Populasi dalam penelitian ini adalah seluruh pegawai Dinas Perkim LH Kabupaten Kebumen dengan jumlah 50 pegawai. Instrumen yang digunakan dalam penelitian ini adalah kuesioner untuk memperoleh data-data primer yang dibutuhkan. Metode penelitian bersifat analisis kuantitatif, data yang diperoleh berdasarkan jawaban dari responden pada kuesioner, dianalisis dengan teknik statistik analisis regresi linear berganda, model regresi diuji dengan asumsi klasik agar memenuhi syarat dan layak dipakai untuk memprediksi pengaruh variabel bebas terhadap variabel terikat. Hasil perhitungan regresi diuji dengan uji t dan koefisien determinasi.
\end{abstract}

Hasil penelitian ini menunjukan bahwa variabel Workplace Friendship dan PersonOrganization Fit berpengaruh Terhadap Organizational Citizenship Behavior melalui Kepuasan Kerja pada pegawai Dinas Perkim LH Kebumen. Dalam penelitian ini diketahui bahwa Workplace Friendship merupakan variabel independen yang pengaruhnya paling besar terhadap Organizational Citizenship Behavior pegawai dibandingkan variabel independen yang lain.

Kata kunci : Workplace Friendship, Person-Organization Fit, Kepuasan Kerja, Organizational Citizenship Behavior.

\section{PENDAHULUAN}

Sumber daya manusia mencakup keseluruhan manusia yang ada di dalam organisasi dari level yang paling bawah sampai level teratas. Sekalipun berbeda level, akan tetapi kesemua sumber daya manusia tersebut memiliki peran yang sama dan signifikan bagi tecapainya tujuan organisasi (Ernie Tisnawati Sule; 2005).

Dinas Perumahan dan Kawasan Permukiman dan Lingkungan Hidup atau biasa disebut Dinas Perkim LH merupakan sebuah organisasi yang mempunyai tujuan melaksanakan pemberdayaan masyarakat melalui program-program tertentu.

Berdasarkan hasil wawancara yang dilakukan dengan Kepala TU, diketahui bahwa salah satu hal yang menjadi masalah di Dinas Perkim LH adalah sedikitnya jumlah pegawai yang bekerja. Selain itu, beban kerja yang diberikan oleh setiap pegawai sangat banyak sehingga mereka harus rela melakukan pekerjaan dengan sistem lembur (overtime). Hari kerja bagi semua pegawai di Dinas Perkim LH ditetapkan lima hari kerja mulai hari Senin sampai dengan hari Jumat dengan jam kerja efektif mulai jam 07.30 sampai dengan 16.00. Akan tetapi, para pegawai di Dinas Perkim LH sering melakukan lembur hingga larut malam. Beberapa pegawai juga dituntut untuk tetap berangkat pada hari Sabtu untuk menyelesaikan pekerjaan yang sudah diberikan. Terdapatnya empat bidang pekerjaan pada Dinas Perkim LH dan masih kurangnya tenaga pegawai menjadikan para pegawai dituntut untuk mempunyai perilaku OCB yang tinggi. 
Berdasarkan hasil wawancara yang telah dilakukan dengan Kepala TU, diketahui bahwa para pegawai di Dinas Perkim LH mempunyai perilaku OCB yang tinggi. Perilaku OCB pegawai pada Dinas Perkim LH diantaranya dibuktikan dengan selalu memperlihatkan perilaku yang positif seperti menolong rekan kerjanya dalam menyelesaikan tugas, memberi informasi antarpegawai di antara bidang, aktif dalam kegiatan kantor, bertindak sesuai prosedur dan memberikan pelayanan yang terbaik. Faktor-faktor yang mempengaruhi OCB pada Dinas Perkim diantaranya yaitu, workplace friendship.

Fenomena workplace friendship pada Dinas Perkim LH adalah kenyataan bahwa mereka bekerja berdasarkan kelompok/tim, sehingga tanpa disadari kedekatan mereka menjadi suatu hubungan yang sangat menguntungkan bagi organisasinya. Menurut wawancara yang dilakukan dengan Kepala TU, diketahui para pegawai di Dinas Perkim LH tampak mengkoordinasikan tindakan mereka dengan lebih baik. Mereka selalu menjalin komunikasi dengan baik dan bersosialisasi terkait masalah pekerjaan. Mereka melakukan hal tersebut juga karena kesadaran terhadap adanya kesesuaian tujuan dan kebutuhan antara sesama rekan kerja dengan organisasi tempat di mana mereka bekerja. Kesesuaian tujuan antara individu dengan organisasi dalam hal ini adalah pemimpin dan rekan sekerja atau biasa disebut dengan person organization fit (P-O Fit).

Fenomena P-O Fit pada Dinas Perkim LH dapat dilihat dari karakteristik individu yang meliputi perilaku, sikap, pendidikan, dan nilai-nilai. Perilaku dan sikap pegawai di Dinas Perkim LH menjadi karakteristik yang paling terlihat dalam mengukur tingkat kesesuaian individu dengan organisasinya. Perilaku pegawai yang senantiasa memperlihatkan rasa senang dalam bekerja sehingga pekerjaan dapat terselesaikan dengan baik dapat menjadi karakteristik kesesuaian tujuan dengan organisasinya. Kesesuaian nilai yang paling dominan antara pegawai dengan Dinas Perkim LH adalah nilai kerja sama dan nilai kecintaannya pada alam.

Perasaan nyaman dan senang dalam melakukan pekerjaan juga merupakan sebuah kepuasan bagi para pegawai sebelum memunculkan perilaku OCB.

Kepuasan kerja merupakan determinan penting yang mendorong seseorang memperlihatkan perilaku OCB, disebabkan karena individu-individu yang mendapatkan kepuasan dalam pekerjaannya, akan cenderung memaknai pekerjaan dan tugas-tugas yang ia laksanakan dengan penuh tanggung jawab dan dedikasi.

Berdasarkan latar belakang tersebut di atas, maka penulis tertarik untuk melakukan penelitian dengan judul "Pengaruh Workplace Friendship dan Person-Organization Fit (PO-Fit) Terhadap Organizational Citizenship Behavior (OCB) dengan Kepuasan Kerja Sebagai Variabel Intervening (Studi pada Dinas Perumahan dan Kawasan Permukiman dan Lingkungan Hidup Kabupaten Kebumen).

\section{KAJIAN TEORI}

Organization Citizenship Behavior (OCB) Organization Citizenship Behavior (OCB) merupakan kontribusi seorang individu yang melebihi tuntutan peran di tempat kerja dan diberi penghargaan berdasarkan hasil kinerja individu. OCB ini melibatkan beberapa perilaku meliputi perilaku tolong-menolong orang lain, menjadi sukarelawan untuk tugas-tugas ekstra, patuh terhadap aturan-aturan dan prosedur-prosedur di tempat kerja.

Organ (1998) mengemukakan bahwa terdapat lima dimensi dari Organization Citizenship Behavior yaitu:

1. Altruism

2. Civic Virtue

3. Conscientiousness

4. Courtesy

5. Sprotmanship

Workplace Friendship

Berman dkk., (2002) mendefinisikan workplace friendship sebagai hubungan kerja nonekslusif secara sukarela yang melibatkan rasa saling percaya, komitmen, keinginan timbal balik dan minat dan nilai bersama. Dotan (2007) mengemukakan ketika karyawan memiliki teman yang dapat dipercaya di tempat kerja, mereka dapat memperoleh bantuan atau saran dari rekan kerja teman mereka dan, karenanya, memperoleh perasaan aman, nyaman, dan 
puas dengan pekerjaan mereka di tempat kerja.

Adapun indikator workplace friendship menurut Nielsen (2000) meliputi: Pengukuran workplace friendship dimensi peluang:

1. Mengenal rekan kerja

2. Bekerja secara kolektif

3. Bebas berkomunikasi

4. Dukungan organisasi

5. Hubungan erat

6. Toleransi

Pengukuran workplace friendship dimensi prevalensi:

7. Keintiman

8. Sosialisasi

9. Berbagi cerita

10. Kepercayaan

11. Motivasi

12. Netral

\section{Person-Organization Fit (P-O Fit)}

Kristof-Brown dan Billsberry (2013), mendefinisikan P-O Fit sebagai kesesuaian antara orang dan organisasi, yang terjadi ketika setidaknya satu pihak memberikan kebutuhan pihak lainnya, atau kedua pihak berbagi karakteristik mendasar yang sama.

Adapun indikator P-O Fit menurut Kristof (1996) meliputi:

1. Kesesuaian nilai (value congruence)

2. Kesesuaian tujuan (goal congruence)

3. Pemenuhan kebutuhan karyawan

4. Kesesuaian karakteristik kultur kepribadian

\section{Kepuasan Kerja}

Kepuasan kerja menurut Robbins (2003), adalah sikap umum terhadap pekerjaan seseorang, yang menunjukan perbedaan antara jumlah penghargaan yang diterima pekerja dan jumlah yang mereka yakini seharusnya mereka terima.

Adapun indikator kepuasan kerja menurut Robbin (2009) meliputi:

1. Kepuasan terhadap pekerjaan itu sendiri

2. Kepuasan terhadap imbalan dari pekerjaan itu

3. Kepuasan terhadap supervisi dari atasan

4. Kepuasan terhadap rekan kerja

5. Kepuasan terhadap promosi

\section{Model Empiris}

Berdasarkan landasarn teori yang telah dibahas, maka dapat disusun suatu model empiris yang digambarkan sebagai berikut:
Gambar 1. Model Empiris

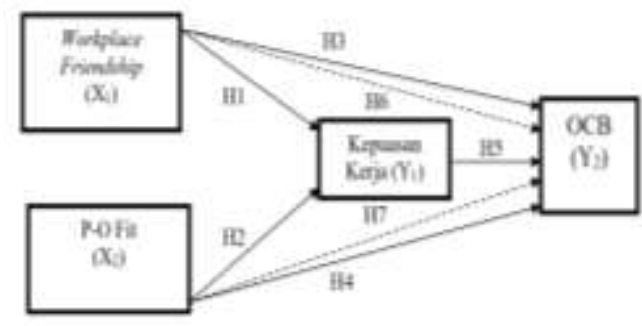

\section{METODE}

Rancangan penelitian ini menggunakan pengujian hipotesis dan penelitian ini menggunakan jenis penelitian kuantitatif. Populasi pada penelitian adalah seluruh pegawai Dinas Perkim LH (Bidang Perumahan, Kawasan Permukiman dan Lingkungan Hidup) Kabupaten Kebumen dan metode pengambilan sampel menggunakan teknik non probability sampling yaitu sampel jenuh dengan jumlah 50 pegawai.

Teknik pengumpulan data yang dilakukan dengan cara: (1) Menyebar kuesioner langsung kepada para pegawai Dinas Perkim LH Kebumen; (2) wawancara; (3) Studi pustaka. Instrumen dalam penelitian ini dilakukan dengan menggunakan kuesioner yang ditunjukan untuk memperoleh jawaban dari responden. Alat bantu pengolahan data menggunakan SPSS for windows versi 22.0 Teknik analisis data dilakukan dengan dua cara yaitu analisis deskriptif dan analisis statistika. Analisis data secara statistika meliputi: (1) Uji validitas dan reliabilitas; (2) Uji Asumsi Klasik; (3) Uji hipotesis; (4) Analisis Korelasi; (5) Analisis Jalur.

\section{HASIL DAN PEMBAHASAN}

\section{Uji Reliabilitas}

Uji reliabilitas butir dilakukan dengan ketentuan jika $r_{\text {alpha }}>0,60$, maka butir atau variabel tersebut reliabel dan sebaliknya

Tabel 1. Uji Reliabilitas

\begin{tabular}{l|c|c|c}
\hline \multicolumn{1}{c|}{ Variabel } & $\begin{array}{c}\text { Nilai } \\
\text { Alpha }\end{array}$ & $\begin{array}{c}\text { Nilai } \\
\text { Kritis }\end{array}$ & Ket \\
\hline $\begin{array}{l}\text { Workplace } \\
\text { Friendship }\left(\mathrm{X}_{1}\right)\end{array}$ & 0,715 & 0,6 & Reliabel \\
\hline P-O Fit $\left(\mathrm{X}_{2}\right)$ & 0,611 & 0,6 & Reliabel \\
\hline $\begin{array}{l}\text { Kepuasan Kerja } \\
\text { (Y })\end{array}$ & 0,655 & 0,6 & Reliabel \\
\hline OCB $\left(\mathrm{Y}_{2}\right)$ reliabilitas butir dilakukan
\end{tabular}

dengan ketentuan jika $r_{\text {alpha }}>0,60$, maka 
butir atau variabel tersebut reliabel dan sebaliknya.

Berdasarkan tabel di atas, hasil analisis dapat dijelaskan bahwa seluruh variabel yang dipakai dalam penelitian ini dinyatakan reliabel karena $r_{\text {alpha }}>0,60$.

Uji Asumsi Klasik

Uji Multikolinieritas

Tabel 2. Hasil Uji Multikolinieritas Sub Struktural I

\begin{tabular}{l|l|l}
\hline \multirow{2}{*}{$\begin{array}{l}\text { Variabel } \\
\text { Bebas }\end{array}$} & \multicolumn{2}{|l}{ Collinierity Statistics } \\
\cline { 2 - 3 } $\begin{array}{l}\text { Torkplace } \\
\text { Friendship } \\
\left(\mathrm{X}_{1}\right)\end{array}$ & 0,511 & VIF \\
\hline P-O Fit $\left(\mathrm{X}_{2}\right)$ & 0,511 & 1,956 \\
\hline
\end{tabular}

Tabel 3. Hasil Uji Multikolinieritas Sub Struktural II

\begin{tabular}{l|c|c}
\hline \multirow{2}{*}{ Variabel Bebas } & \multicolumn{2}{|c}{ Collinierity Statistics } \\
\cline { 2 - 3 } & Tolerance & VIF \\
\hline $\begin{array}{l}\text { Workplace } \\
\text { Friendship }\left(\mathrm{X}_{1}\right)\end{array}$ & 0,431 & 2.323 \\
\hline P-O Fit $\left(\mathrm{X}_{2}\right)$ & 0,406 & 2.465 \\
\hline $\begin{array}{l}\text { Kepuasan Kerja } \\
(\mathrm{Y} 1)\end{array}$ & 0,403 & 2.479 \\
\hline
\end{tabular}

Berdasarkan tabel diatas, model regresi pada penelitian ini tidak terjadi multikolinieritas karena nilai tolerance lebih dari 0,1 dan nilai VIF kurang dari 10 .

\section{Uji Heteroskedastisitas}

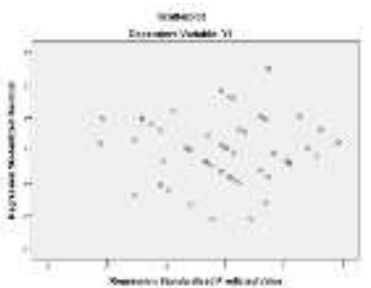

Gambar 2. Uji Heteroskedastisitas Sub Struktural I

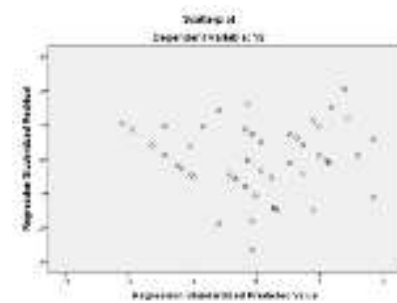

Gambar 3. Uji Heteroskedastisitas Sub Struktural II

Berdasarkan gambar diatas, model regresi pada penelitian ini bebas dari heteroskedatisitas karena tidak ada pola tertentu yang jelas.

\section{Uji Normalitas}

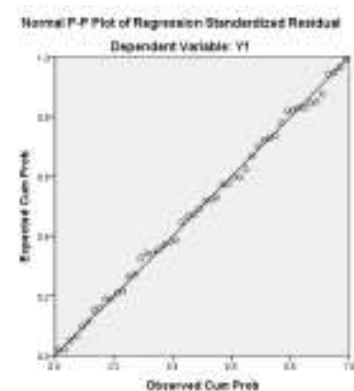

Gambar 4. Uji Normalitas Sub Struktural I

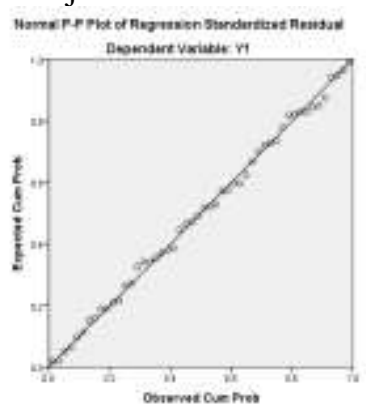

Gambar 5. Uji Normalitas Sub Struktural II

Berdasarkan gambar di atas, diketahui bahwa data menyebar di sekitar garis diagonal dan mengikuti arah garis diagonal, maka model memenuhi asumsi normalitas.

\section{Uji Hipotesis}

1. Uji Parsial

Tabel 4. Uji t Sub Struktural I

\begin{tabular}{|c|c|c|c|c|c|}
\hline \multirow[b]{3}{*}{ Model } & \multicolumn{4}{|c|}{ Coefficients $^{\mathrm{a}}$} & \\
\hline & \multicolumn{2}{|c|}{$\begin{array}{c}\text { Unstandardiz } \\
\text { ed } \\
\text { Coefficients }\end{array}$} & \begin{tabular}{|c|} 
Standar \\
dized \\
Coeffic \\
ients \\
\end{tabular} & \multirow[b]{2}{*}{$\mathrm{t}$} & \multirow[b]{2}{*}{ Sig. } \\
\hline & $\mathrm{B}$ & $\begin{array}{c}\text { Std. } \\
\text { Error }\end{array}$ & Beta & & \\
\hline $\begin{array}{l}\text { (Cons } \\
\operatorname{tant})\end{array}$ & $\begin{array}{r}1.33 \\
3\end{array}$ & 2.146 & & .621 & .538 \\
\hline $\mathrm{X} 1$ & .222 & .075 & .384 & 2.966 & .005 \\
\hline $\mathrm{X} 2$ & .531 & .152 & .453 & 3.496 & .001 \\
\hline
\end{tabular}

a. Workplace Friendship tidak berpengaruh positif dan signifikan terhadap kepuasan kerja karena $t_{\text {hitung }}$ sebesar 2,966 $>t_{\text {tabel }}$ sebesar 2,01290 dan nilai signifikansi sebesar $0,005=0,005$ 
b. P-O Fit berpengaruh positif dan signifikan terhadap kepuasan kerja karena $t_{\text {hitung }}$ sebesar 3,496>tabel sebesar 2,01290 dan nilai signifikansi sebesar $0,001<0,005$.

Tabel 5. Uji t Sub Struktural II

\begin{tabular}{|c|c|c|c|c|c|}
\hline \multicolumn{6}{|c|}{ Coefficients $^{\mathrm{a}}$} \\
\hline \multirow[b]{2}{*}{ Model } & \multicolumn{2}{|c|}{$\begin{array}{l}\text { Unstandardi } \\
\text { zed } \\
\text { Coefficients }\end{array}$} & \multirow{2}{*}{$\begin{array}{c}\text { Standar } \\
\text { dized } \\
\text { Coeffic } \\
\text { ients } \\
\text { Beta } \\
\end{array}$} & \multirow[b]{2}{*}{$\mathrm{t}$} & \multirow[b]{2}{*}{ Sig. } \\
\hline & & $\begin{array}{c}\text { Std. } \\
\text { Error }\end{array}$ & & & \\
\hline $\begin{array}{l}\text { (Cons } \\
\operatorname{tant})\end{array}$ & $\begin{array}{r}1.69 \\
4\end{array}$ & $\begin{array}{r}1.96 \\
8\end{array}$ & & .861 & .394 \\
\hline $\mathrm{X} 1$ & .245 & .074 & .397 & $\begin{array}{r}3.29 \\
7\end{array}$ & .002 \\
\hline $\mathrm{X} 2$ & .207 & .156 & .165 & $\begin{array}{r}1.32 \\
8\end{array}$ & .191 \\
\hline X3 & .401 & .133 & .374 & $\begin{array}{r}3.01 \\
2\end{array}$ & .004 \\
\hline
\end{tabular}

Berdasarkan tabel diatas menunjukan bahwa:

a. Workplace Friendship berpengaruh positif dan signifikan terhadap OCB karena $t_{\text {hitung }}$ sebesar 3,297>tabel sebesar 2,01290 dan nilai signifikansi sebesar $0,002<0,005$

b. P-O Fit tidak berpengaruh positif dan signifikan terhadap OCB karena $t_{\text {hitung }}$ sebesar 1,328 < $t_{\text {tabel }}$ sebesar 2,01290 dan nilai signifikansi sebesar $0,191>$ 0,05

c. Kepuasan kerja berpengaruh positif dan signifikan terhadap OCB karena $t_{\text {hitung }}$ sebesar 3,012 < $t_{\text {tabel }}$ sebesar 2,01290 dan nilai signifikansi sebesar $0,004<$ 0,005

\section{Koefisien Determinasi}

Tabel 6. Uji Koefisien Determinasi Sub Struktural I

\begin{tabular}{|c|c|c|c|c|}
\hline \multicolumn{5}{|c|}{ Model Summary $^{\mathbf{b}}$} \\
\hline $\begin{array}{l}\text { Mo } \\
\text { del }\end{array}$ & $\mathrm{R}$ & $\begin{array}{c}\mathrm{R} \\
\text { Square }\end{array}$ & $\begin{array}{c}\text { Adjusted R } \\
\text { Square }\end{array}$ & $\begin{array}{c}\text { Std. Error of the } \\
\text { Estimate }\end{array}$ \\
\hline 1 & $947^{a}$ & ,896 &, 886 & ,71106 \\
\hline \multicolumn{5}{|c|}{ a. Predictors: (Constant), Total X2, Total X1 } \\
\hline \multicolumn{5}{|c|}{ b. Dependent Variable: Total Y2 } \\
\hline
\end{tabular}

Berdasarkan output di atas dapat dilihat nilai Adjusted $R$ Square 0,886 atau dapat diartikan sebesar $88,6 \%$ OCB pegawai
Dinas Perkim LH Kabupaten Kebumen dipengaruhi oleh workplace friendship $\left(\mathrm{X}_{1}\right)$ dan P-O Fit $\left(\mathrm{X}_{2}\right)$, sedangkan sisanya $11,4 \%$ dipengaruhi oleh variabel lain.

Tabel 7. Uji Koefisien Determinasi Sub Struktural II

\begin{tabular}{l}
\begin{tabular}{l|c|c|r|c}
\hline \multicolumn{4}{c}{ Model Summary $^{\mathbf{b}}$} \\
\hline del & $\mathrm{R}$ & $\begin{array}{c}\mathrm{R} \\
\text { Square }\end{array}$ & $\begin{array}{r}\text { Adjusted } \\
\text { R Square }\end{array}$ & $\begin{array}{c}\text { Std. Error of the } \\
\text { Estimate }\end{array}$ \\
\hline 11 & .845 & .713 & .695 & 1.12666 \\
\hline
\end{tabular} \\
a. Predictors: (Constant), Total Y1, Total \\
X2, Total X1 \\
\hline
\end{tabular}

Berdasarkan output di atas dapat dilihat nilai koefisien determinasi Adjusted $R$ Square diperoleh 0,695 atau dapat diartikan sebesar 69,5\% OCB pegawai Dinas Perkim LH dipengaruhi oleh variabel Workplace Friendship $\left(\mathrm{X}_{1}\right)$, P-O Fit $\left(\mathrm{X}_{2}\right)$ dan Kepuasan Kerja $\left(\mathrm{Y}_{1}\right)$, sedangkan sisanya $30,5 \%$ disebabkan oleh variabel lain yang tidak ada dalam penelitian ini.

\section{Analisis Korelasi}

Tabel 8. Hasil Uji Korelasi

\begin{tabular}{|c|c|c|c|c|}
\hline \multicolumn{5}{|c|}{ Correlations } \\
\hline & & $\begin{array}{c}\text { Total } \\
\text { X1 }\end{array}$ & $\begin{array}{c}\text { Total } \\
\text { X2 }\end{array}$ & $\begin{array}{c}\text { Total } \\
\text { Y1 }\end{array}$ \\
\hline \multirow[t]{3}{*}{$\begin{array}{l}\text { Total } \\
\text { X1 }\end{array}$} & $\begin{array}{l}\text { Pearson } \\
\text { Correlation }\end{array}$ & 1 & $.699^{* *}$ & $.701^{* *}$ \\
\hline & Sig. (2-tailed) & & .000 & .000 \\
\hline & $\mathrm{N}$ & 50 & 50 & 50 \\
\hline \multirow[t]{3}{*}{$\begin{array}{l}\text { Total } \\
\mathrm{X} 2\end{array}$} & $\begin{array}{l}\text { Pearson } \\
\text { Correlation }\end{array}$ & $.699^{* *}$ & 1 & $.722^{* *}$ \\
\hline & Sig. (2-tailed) & .000 & & .000 \\
\hline & $\mathrm{N}$ & 50 & 50 & 50 \\
\hline \multirow[t]{3}{*}{$\begin{array}{l}\text { Total } \\
\text { Y1 }\end{array}$} & $\begin{array}{l}\text { Pearson } \\
\text { Correlation }\end{array}$ & $.701^{* *}$ & $.722^{* *}$ & 1 \\
\hline & Sig. (2-tailed) & .000 & .000 & \\
\hline & $\mathrm{N}$ & 50 & 50 & 50 \\
\hline $\begin{array}{l}* * . C \\
(2-t a\end{array}$ & elation is si & int & 0.01 & \\
\hline
\end{tabular}

Berdasarkan tabel di atas, nilai korelasi workplace friendship terhadap P-O Fit sebesar 0,699 dan angka singnifikansi sebesar $0,000<0,05$, artinya antara variabel workplace friendship dan P-O Fit memiliki korelasi yang kuat dan signifikan. 
Implikasi Manajerial

Setelah melakukan analisis penulis membuat implikasi manajerial sebagai berikut :

1. Pengaruh Workplace Friendship Terhadap Kepuasan Kerja

Berdasarkan hasil uji t diperoleh bahwa terdapat pengaruh yang tidak signifikan antara workplace friendship terhadap kepuasan kerja. Pengaruh workplace friendship yang tidak signifikan terhadap kepuasan kerja mengidentifikasikan bahwa tinggi rendahnya tingkat workplace friendship di Dinas Perkim LH tidak mempengaruhi tinggi rendahnya tingkat kepuasan kerja para pegawai. Hal ini dikarenakan tingkat persahabatan yang ada pada Dinas Perkim LH tidak begitu memberi banyak kontribusi terhadap rasa puas pada pekerjaan, yang artinya nilai persahabatan tinggi tidak memberikan rasa puas dalam hal penyelesaian pekerjaannya.

Hasil penelitian ini berbeda dengan hasil penelitian yang dilakukan oleh Reza Asgharian tahun 2015 dengan judul The Mediating Effect of Job Satisfaction on the Relationship between Workplace Friendships and Turnover Intention in Iran Hotel Industry. Penelitian tersebut menyatakan bahwa workplace friendship memiliki pengaruh signifikan terhadap kepuasan kerja.

2. Pengaruh P-O Fit Terhadap Kepuasan Kerja

Berdasarkan hasil uji $\mathrm{t}$ diperoleh bahwa P-O Fit memiliki pengaruh yang signifikan terhadap kepuasan kerja. Pengaruh P-O Fit yang positif dan signifikan mengidentifikasikan bahwa pegawai sudah merasa cocok dengan nilai yang ada pada Dinas Perkim LH, dan tujuan pegawai sesuai dengan tujuan organisasi. Hal tersebut ditandai dengan para pegawai yang menyukai sistem bekerja dengan sistem kerja sama/tim dan kecintaannya bekerja di lapangan yang sesuai dengan nilai pada Dinas Perkim LH.

3. Pengaruh Workplace Friendship
Terhadap OCB
Berdasarkan hasil uji t diperoleh bahwa workplace friendship memiliki pengaruh yang signifikan terhadap OCB. Pengaruh workplace friendship yang positif dan signifikan mengidentifikasikan bahwa workplace friendship akan berbanding lurus dengan OCB. Apabila workplace friendship mengalami peningkatan maka OCB juga akan mengalami peningkatan. Semakin tinggi tingkat persahabatan di Dinas Perkim LH, maka akan semakin meningkatkan perilaku OCB. Hal ini dikarenakan persahabatan mendorong empati dan dapat berbagi masalah sehingga memunculkan perilaku tolongmenolong.

Hasil penelitian ini didukung oleh penelitian yang dilakukan oleh ChiaMing Chang, dkk., tahun 2018 dalam penelitiannya yang berjudul The Impact of Perceived Supervisor Support and Workplace Friendship on Organization Citizenship Behavior in Suport Center. Penelitian tersebut menyatakan bahwa workplace friendship memiliki pengaruh signifikan terhadap OCB.

4. Pengaruh P-O Fit Terhadap OCB

Berdasarkan hasil uji $\mathrm{t}$ diperoleh bahwa terdapat pengaruh yang tidak signifikan antara P-O Fit terhadap OCB. $\mathrm{P}-\mathrm{O}$ Fit yang tidak memiliki pengaruh terhadap OCB mengidentifikasikan bahwa tinggi rendahnya tingkat P-O Fit di Dinas Perkim LH tidak akan mempengaruhi perilaku OCB para pegawai.

Hasil penelitian ini berbeda dengan hasil penelitian yang dilakukan oleh Putri Marita Abdurachman (2017), dalam penelitiannya yang berjudul Pengaruh Hubungan antara PersonOrganization Fit (P-O Fit) Dengan Organization Citizenship Behaviour (OCB) Pada Karyawan PT. Central Proteina Prima Jakarta. Penelitian tersebut menyatakan bahwa PersonOrganization Fit (P-O Fit) memiliki pengaruh positif dan signifikan terhadap OCB.

5. Pengaruh Kepuasan Kerja Terhadap OCB

Berdasarkan hasil uji t diperoleh bahwa workplace friendship memiliki pengaruh yang signifikan terhadap OCB. 
Pengaruh workplace friendship yang positif dan signifikan mengidentifikasikan bahwa workplace friendship akan berbanding lurus dengan OCB. Apabila kepuasan kerja pegawai mengalami peningkatan maka perilaku OCB juga akan mengalami peningkatan. Hal tersebut didasari dari tercapainya rasa puas para pegawai di Dinas Perkim LH atas terselesaikannya semua pekerjaan maka perilaku OCB seperti menolong rekannya yang masih mempunyai tanggungan pekerjaan terbilang tinggi. Mereka akan lebih berinisiatif dan sukarela membantu rekannya yang membutuhkan bantuan

\section{PENUTUP}

\section{Kesimpulan}

Berdasarkan hasil penelitian mengenai Pengaruh Workplace Friendship dan Person-Organization Fit (PO-Fit) Terhadap Organizational Citizenship Behavior (OCB) dengan Kepuasan Kerja Sebagai Variabel Intervening (Studi pada Dinas Perumahan dan Kawasan Permukiman dan Lingkungan Hidup Kabupaten Kebumen) yang telah dibahas serta perhitungan statistik yang dilakukan, maka peneliti dapat menarik kesimpulan sebagai berikut :

1. Workplace Friendship tidak memiliki pengaruh positif dan signifikan terhadap kepuasan kerja di Dinas Perkim LH Kabupaten Kebumen. Hal ini mengidentifikasikan bahwa tinggi rendahnya tingkat $\mathrm{P}-\mathrm{O}$ Fit di Dinas Perkim LH tidak akan mempengaruhi perilaku OCB para pegawai.

2. Person-Organization Fit memiliki pengaruh positif dan signifikan terhadap kepuasan kerja di Dinas Perkim LH Kabupaten Kebumen. Artinya semakin tinggi kesesuaian antara nilai-nilai individu dan nilai-nilai organisasi maka akan meningkatkan kepuasan kerja pegawai.

3. Workplace Friendship memiliki pengaruh positif dan signifikan terhadap OCB di Dinas Perkim LH Kabupaten Kebumen. Artinya semakin tinggi tingkat persahabatan di tempat kerja, maka akan meningkatkan perilaku OCB para pegawai.
4. Person-Organization Fit tidak berpengaruh terhadap OCB di Dinas Perkim LH Kabupaten Kebumen. Dapat disimpulkan bahwa kesesuaian antara nilai-nilai individu dengan nilai-nilai organisasi tidak berpengaruh terhadap perilaku OCB pegawai.

5. Kepuasan Kerja memiliki pengaruh positif dan signifikan terhadap OCB di Dinas Perkim LH Kabupaten Kebumen. Artinya semakin tinggi tingkat kepuasan pegawai dalam bekerja maka akan meningkatkan perilaku OCB para pegawai.

6. Workplace Friendship memiliki pengaruh terhadap OCB melalui kepuasan kerja di Dinas Perkim LH Kabupaten Kebumen. Hal tersebut berarti bahwa semakin tinggi tingkat persahabatan di tempat kerja maka akan semakin tinggi tingkat kepuasan kerja para pegawai yang secara tidak langsung berpengaruh terhadap perilaku OCB.

7. Person-Organization Fit memiliki pengaruh terhadap OCB melalui kepuasan kerja di Dinas Perkim LH Kabupaten Kebumen. Hal tersebut berarti bahwa semakin tinggi tingkat kesesuaian nilai antara individu dengan organisasi maka akan semakin tinggi tingkat kepuasan kerja para pegawai yang secara tidak langsung berpengaruh terhadap perilaku OCB.

\section{Saran}

Berdasarkan kesimpulan yang telah dipaparkan, penulis memberikan saran :

1. Hasil penelitian menunjukan bahwa workplace friendship memiliki pengaruh positif dan signifikan terhadap OCB melalui kepuasan kerja di Dinas Perkim LH Kabupaten Kebumen. Oleh karena itu penulis menyarankan kepada Kepala Dinas Perkim LH untuk meningkatkan kesempatan bagi para pegawainya dalam mengenal rekan kerja dan memberikan kesempatan berbicara secara informal kepada para pegawai. Hal tersebut bisa dilakukan dengan mengadakan pertemuan yang bersifat terbuka dengan tujuan agar lebih saling mengenal dan memungkinkan terciptanya kebersamaan satu sama lain dan memberikan toleransi kepada pegawai untuk berbicara dengan bahasa informal selama saat pekerjaan 
selesai. Selain itu, Kepala Dinas Perkim LH diharapkan tetap mempertahankan tingkat persahabatan yang telah terjalin di dalamnya dengan saling memberi motivasi, dukungan, perasaan nyaman dan rasa percaya antar pegawai.

2. Hasil penelitian menunjukan bahwa Person-Organization Fit memiliki pengaruh positif dan signifikan terhadap kepuasan kerja di Dinas Perkim LH Kabupaten Kebumen. Hal ini mengindikasikan bahwa pegawai merasa cocok dengan tempat dimana mereka bekerja. Oleh karena itu, Dinas Perkim LH sebaiknya mempertahankan nilai kepedulian yang sudah ada melalui pelayanan yang baik serta tanggap terhadap masyarakat dan mengadakan sosialisasi terkait program yang akan dijalankan. Dinas Perkim LH diharapkan juga dapat meningkatkan kesesuaian nilai-nilai pegawai dengan nilai organisasi melalui sistem kerjasama dalam menyelesaikan pekerjaan dan melakukan perekrutan yang setidaknya memiliki nilai, kepribadian individu yang sama dengan organisasinya.

3. Kepuasan Kerja memiliki pengaruh positif dan signifikan terhadap OCB di Dinas Perkim LH Kabupaten Kebumen. Berdasarkan hasil tersebut maka penulis menyarankan untuk organisasi agar dapat meningkatkan penghargaan bagi para pegawainya terutama pemberian upah secara adil dan merata. Pemberian upah tambahan bisa diberikan kepada pegawai yang berprestasi ataupun pegawai yang telah bersedia bekerja lembur diluar jam aktif kerja. Pemberian tambahan upah dapat meningkatkan kepuasan bagi pegawai. Selain itu, Kepala Dinas Perkim LH diharapkan tetap menjaga hubungan dengan para pegawainya agar kepuasan kerja pegawai terus meningkat.

\section{Keterbatasan Penelitian}

Penelitian ini belum dapat mengungkapkan secara keseluruhan faktor yang mempengaruhi perilaku OCB di Dinas Perkim LH, penelitian ini hanya terbatas pada faktor workplace friendship, personorganization fit dan kepuasan kerja..

\section{Penelitian Selanjutnya}

Penelitian selanjutnya juga diharapkan untuk memperluas ruang lingkup wilayah penelitian dan lokasi penelitian sehingga hasil penelitian dapat diimplementasikan secara umum..

\section{DAFTAR PUSTAKA}

Achmad, Kuncoro. (2001). Cara Menggunakan dan Memaknai Analisis Asumsi Klasik, Cetakan Pertama. Bandung: ALFABETA.

Arikunto. (2006). Prosedur Penelitian Suatu Pendekatan Praktek. Jakarta : PT. Rineka Cipta.

(2009). Prosedur penelitian. Jakarta: PT. Rineka Cipta.

Astuti, Darmi Sih. (2010). "Model Person Organization Fit (PO-Fit Model) terhadap Kepuasan Kerja, Komitmen Organisasional dan Kinerja Karyawan”. Jurnal Bisnis dan Ekonomi (JBE). Vol.17 No.1

Azeem, Syed Mohammad. (2010). "Job Satisfaction and Organizational Commitment among Employees in the Sultanate of Oman". Journal Psychology, Vol. 1. p. 295-299.

Berman, dkk. (2002). Workplace relations: Friendship Patterns and Consequences (According to managers). Public Administration Review.

Chatman, J. A. (1989). Improving Interactional Organizational Research: A Model of PersonOrganization Fit.

Dergibson Siagian dan Sugiarto. (2000). Metode Statistika untuk Bisnis dan Ekonomi. Jakarta: PT Gramedia Pustaka Utama

Djarwanto, PS dan Subagyo, Pangestu. (1993). Statistik Induktif. Edisi Ke-empat. Yogakarta: BPFE.

Dotan, H. (2007). Friendship Ties at Work: Origins, Evolution and Consequences for Managerial Effectiveness (Unpublished Doctoral Dissertation). University 
of California, Los Angeles. Los Angeles, CA

Tisnawati, Ernie. (2005). Pengantar Manajemen, Edisi Pertama. Depok: Prenadamedia Group.

Echdar, Saban. (2017). Metode Penelitian Manajemen dan Bisnis. Bogor: Ghalia Indonesia

Fehr, B. (1996). Friendship processes. Thousand Oaks, CA: Sage.

Fine, G. (1986). Friendship in the workplace. In V.J. Derlega, and B.A. Winstead (Eds.). Friendship and Social Interaction (pp. 185206). New York, NY: SpringerVerlag.

Garay, H.D.V. (2006). Kinerja Extra-Role dan Kebijakan Kompensasi, SINERGI, Kajian Bisnis dan Manajemen, Vol. 8 No.1, Januari 2006.

Ghozali, Imam. (2001). Aplikasi Analisis Multivariate dengan Program SPSS. Edisi Kedua. Semarang: Badan Penerbit Universitas Diponegoro.

(2005). Aplikasi Analisis Multivariate dengan SPSS. Semarang: Badan Penerbit UNDIP

. (2009). “Aplikasi Analisis Multivariate dengan Program SPSS “. Semarang : UNDIP.

Greenberg, J. And Robert A. Baron. (2003). Behavior in Organization International Edition, New Jersey: Prentice Hall.

Hadi, Sutrisno. (1991). Analisa Butir untuk Instrument. Edisi pertama. Andi Offset: Yogyakarta

Hajar, Ibnu. (1999). Dasar-Dasar Penelitian Kuantitatif dalam Pendidikan. Jakarta: Raja Grafindo Persada
Kreitner, Robert and Angelo Kinicki, (2001). Organizational Behavior. Fifth Edition. Irwin McGraw-Hill.

Kristof, A.L. (1996). Person-organization fit: An Integrative Review of its Conceptualizations, Measurement, and Implications. Personnel Psychology, 49, 1, 149.

(2013). Organization Fit: Key Issues and New Directions. A John Wilye dan Sons, Ltd, Publication.

Malayu, S.P. Hasibuan, (2007). Manajemen Sumber Daya Manusia. Jakarta : Cetakan 9. PT. Bumi Aksara.

Meyer, P. John., and Herscovitch, Lynne. (2001). Commitment in the Workplace Toward a General Model. Human resource management review, 11, 299-326.

Muchinsky, P. M., \& Monahan, C. J. (1987). What is Person-Environment Congruence?

Nielsen, I.K., Jex, S.M., \& Adams, G.A. (2000). Development and Validation of Scores on a Twodimensional Workplace Friendship Scale. Educational and Psychological Measurement, 60, 628-643.

Organ, D. W. (1994). Personality and Organizational Citizenship Behavior. Journal of Management, 20, pp. 465-478.

Podsakoff P. M., MacKenzie, S. B. (2006). Organizational Citizenship Behavior: Its Nature, Antecedents and Consequences. Sage Publication

Riduwan \& Akdon. (2009). Rumus dan Data dalam Analisis Statistika. Bandung: Alfabeta. 
Riduwan, (2010). Skala Pengukuran Variabel-Variabel Penelitian. Bandung: Alfabeta.

Riduwan \& Kuncoro. (2011). Cara Menggunakan dan Memakai Path Analysis (Analisis Jalur). Bandung: Alfabeta

Robbins SP, dan Judge. (1998). Perilaku Organisasi, Buku 2, Jakarta: Salemba Empat.

(2008). Perilaku Organisasi Buku 2, Jakarta: Salemba Empat.

Silverthorne, Colin. (2004). The Impact of Organizational Culture and Person Organization Fit on Organizational Commitment and Job Satisfaction in Taiwan. The Leadership \& Organization Development Journal, 25, (7), 592-599. Sinergi Kajian Bisnis dan Manajemen, Vol. 8, No. 1, 33-42.

Song,S. (2005). Workplace Friendship and its Impact on Employees' Positive Work Attitudes: A Comparative Study of Seoul City and New Jersey State Government Public Officials (Unpublished Doctoral Dissertation). Rutgers, The State University of New Jersey. Newark, NJ.

Sugiyono. (2012). Metode Penelitian Kuantitatif Kualitatif dan $R \& D$. Bandung: Alfabeta.

Sugiyono. (2014). Metode Penelitian Pendidikan Pendekatan Kuantitatif, Kualitatif, dan $R \& D$. Bandung: Alfabeta.

Uhl-Bien, Mary, Schermerhorn, Jr., John R., Osborn, Richard N. (2014). Organizational Behavior, Experience Grow Contribute (13th ed). 222 Rosewood Drive, Danvers, MA 01923: Clearance Center, Inc.
Van Dyne, L., Graham, J. W., \& Dienesch, R. M. (1994). Organizational Citizenship Behavior: Construct Redefinition, Measurement, and Validation. Academy of Management Journal. 37 (4): $7 \square \square-802$. Supplementary versus complementary models of fit. Journal of Vocational Behavior, 31, 268-277.

Vecchio, Robert, P. (1995). Organizational Behavior. Florida: Harcourt BraceCollege Publishers.

Werther, William B. \& Keith Davis. 1996. Human Resources and Personal Management. International Edition. McGraw-Hiil, Inc., USA. 